\title{
Contemporary vaccination policy in the European Union: tensions and dilemmas
}

\author{
Katharina T. Paul ${ }^{1} \cdot$ Kathrin Loer ${ }^{2}$
}

Published online: 20 March 2019

(C) The Author(s) 2019

\begin{abstract}
This paper seeks to contribute to a more nuanced discourse on vaccination policy. Current polarization between either mandatory and entirely voluntary is misleading, as virtually all immunization programs feature a combination of instruments that comprise mandatory and voluntary elements. We develop this argument by presenting five case studies from the European Union (EU). By systematically acknowledging the nuances of political and institutional varieties, we build the case for reframing the terms of the debate in the EU and beyond.
\end{abstract}

Keywords Vaccination · Policy $\cdot$ European Union (EU) $\cdot$ National immunization systems $\cdot$ Institutions

\section{Introduction}

Following a decrease in uptake of vaccines and the risks of failing to achieve 'herd immunity' [1], we have been witnessing the re-emergence of mandatory vaccination schemes in certain European healthcare systems (e.g., France, Italy). We acknowledge the wide spectrum of meanings of the term 'herd immunity' in the public health literature [2]. For the sake of our argument, we refer to it as denoting the 'herd effect.' This is reached if the 'density of susceptible individuals to exceed a critical value such that, on average, each primary case of infection generates at least

Both authors contributed equally to this work.

Katharina T. Paul

katharina.t.paul@univie.ac.at

Kathrin Loer

kathrin.loer@fernuni-hagen.de

1 Department of Political Science, University of Vienna, Universitätsstrasse 7, 1010 Vienna, Austria

2 Department of Political Science, FernUniversität in Hagen, Universitätsstrasse 33, 58084 Hagen, Germany 
one secondary case [...] the level of herd immunity must simply be sufficient to reduce the susceptible fraction below the critical point" [3]

Policy changes have been accompanied by media coverage that tends to accentuate the polarized nature of the vaccination debate. In this article, we seek to evaluate the terms of the debate and to argue for a more nuanced policy discourse. Such a change would, in our view, require a shift away from the binary distinctions that have characterized vaccination policy: labels of 'pro' or 'anti' vaccination, and distinctions between voluntary and mandatory vaccination.

We favor a systematic acknowledgement of the nuances of political and institutional diversity, because this knowledge is crucial to both the improvement of vaccination regimes and to a more sophisticated political debate. We will show that each type of vaccination program both reflects and reproduces historically and cultureshaped state-society relationships [4].

To this end, we present five paradigmatic examples-Austria, Germany, Italy, France, and the Netherlands - to show that no two national immunization programs (NIPs) are alike, and that all feature different and culturally contingent understandings of 'voluntary' and 'mandatory,' resulting in a nationally specific NIP (Fig. 1). Our case selection has been informed by practical considerations and by our prior research experience. Our sample is thus skewed heavily toward the Western Europe. Including a wider range of cases-particularly post-communist Central and Eastern European countries-would undoubtedly lead to a richer account. Notwithstanding this bias in our case selection, we will focus specifically on three axes of difference:

- general principles and institutional structures in light of recent changes to national immunization programs (where such changes have occurred);

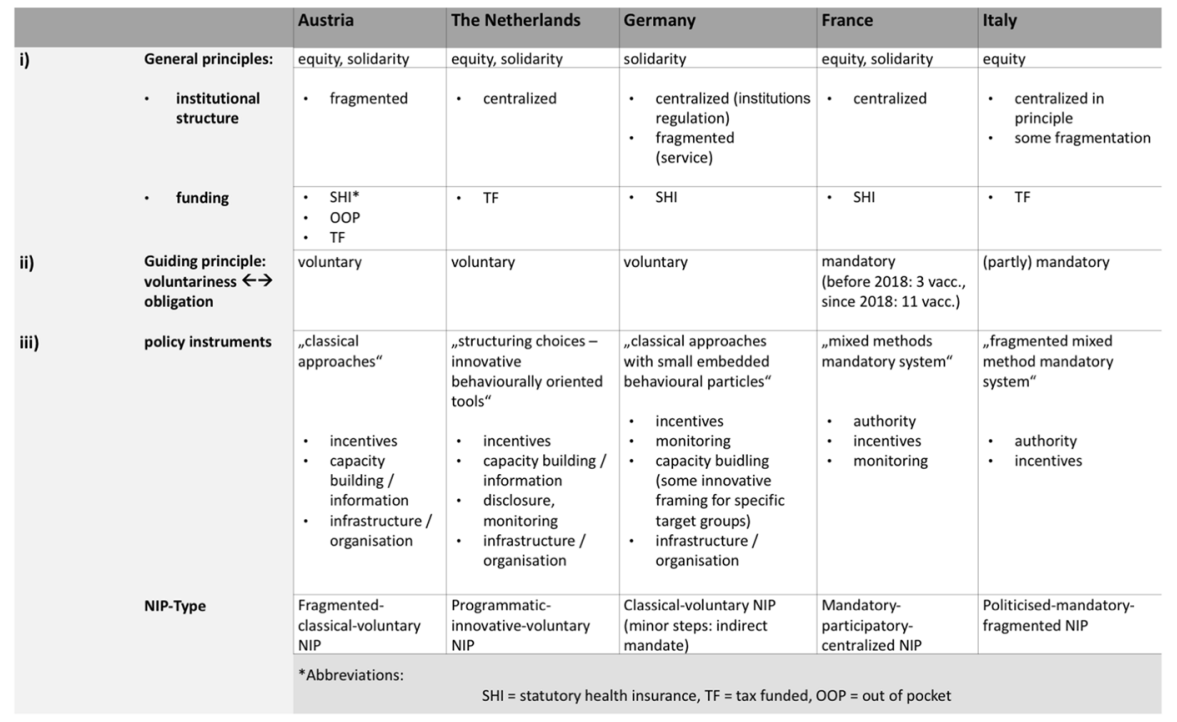

Fig. 1 National immunization programs: Political and institutional varieties 
- guiding principles, ranging from free choice to obligation; and

- political and institutional interventions through use of specific policy instruments to incentivize (pro) vaccination behavior.

In our review of policy instruments, we use a four-type classification of (1) highly coercive instruments (e.g., mandatory vaccination) (2) behavioral tools that modify citizens' 'choice architecture' without coercion and informed by insights from behavioral sciences (3) capacity building/information, and (4) organization/infrastructure. All four types may also occur in hybrid forms and be reinforced using behavioral insights [5]. We contextualize this comparison by referring to the main arguments that are currently shaping policy discourses in each country, and we also draw on a systematic analysis of social science literature on vaccination policy and of reports issued by national immunization programs and the World Health Organization (WHO).

\section{Context: toward a European public in public health?}

As some commentators note, vaccination policy appears to be the victim of its own success: a number of serious vaccine-preventable diseases, such as polio and measles, have virtually disappeared in many regions, due to effective vaccination programs; the consequences of these diseases are no longer visible in everyday life. Conversely, "rare reactions to vaccines" have seemingly become "more visible and feared" among certain segments of the population and now receive what appears to be a disproportionately high level of publicity [1]. Thus, the very invisibility of vaccine-preventable diseases is undermining the practice of vaccination itself. At the same time, vaccination has always been a decidedly political issue. Across Europe, state-sponsored mass vaccination programs have repeatedly led to heated political debate, whether about pertussis vaccination (against whooping cough) in the 1970s [6], the measles, mumps, rubella (MMR) vaccine, the vaccine against H1N1, Hepatitis B [7], or the vaccine against Human Papilloma Virus (HPV) [8].

Every NIP_-and the institutional set-up of national public health systems themselves-constitutes a unique reflection of the history of these debates as well as a specific relationship between state and society in a given national context. The reasons why some citizens remain unvaccinated vary widely [9]. This fragmentation, however, is seldom reflected in policy debates. The discourse frequently polarizes people between those who vaccinate and the 'anti-vaxxers.'

Similarly, no two NIPs are alike. Recent data from the European Centre of Disease Prevention and Control (ECDC) shows that 12 member states feature at least one vaccination that is mandatory; and with the exception of Belgium, these countries provide a range of vaccines that are part of a mandatory schedule $[10,11]$. International Health Regulations (IHR) are only pertinent to the extent that any outbreaks of an extensive list of diseases must be reported to both the WHO and the EU authorities to improve joint monitoring. When it comes to prevention, however, NIPs differ tremendously in terms of both the range of vaccines that are offered and funded, and who is entitled to administer them and where. Mandatory immunization 
is, in effect, a rare practice, and is more commonly associated with communist forms of government [12]. One area where mandatory vaccination is more common is for specific population groups - such as military or healthcare workers. Since the latter part of the twentieth century, modern liberal democracies have tended to use less coercive policy instruments. They have relied on vaccination campaigns, parental initiative, and governance through public health institutions (e.g., mother-childhealth programs, youth services).

The European Union has no formal remit with regard to public health. Despite this lack of institutional remit, EU actors have recently called for enhanced cooperation to increase vaccine uptake. In response, the European Academies Science Advisory Council (EASAC) and the Federation of European Academies of Medicine (FEAM) have warned the European Commission against a 'one-size-fits-all' approach to improving vaccination coverage [12]. We echo this warning, and offer a social scientific perspective to back it up. As social science research has shown, NIPs are historically evolved and contextually contingent configurations of state, science, and society [6, 7, 13, 14]. Policymakers draw on specific cultural, ethical, and experiential forms of knowledge-just as biomedical experts often draw on diverging forms of evidence to recommend particular courses of action. The five examples that we present below offer insight into how these differences matter. We will concentrate on the political dimensions of vaccination programs, while acknowledging that joint efforts are needed to improve the safety and effectiveness of vaccines. Overall, our review may be used as an argument for strengthening NIPs in the light of the need to preserve herd immunity [1] as a matter of solidarity across generations and political borders.

Our analysis reflects ongoing research and a review of pertinent literature and policy documents. An initial overview of data served as a basis for drafting a systematic matrix (Fig. 1) that we then used as a framework for our case studies. In addition, we consulted national and European documents and databases. Specifically, the European Centre of Disease Prevention and Control (ECDC) offers an open research archive that allows for a comparison of national immunization programs [15]. We were able to explore, for example, the different classifications of target groups for particular vaccines and attempts to harmonize vaccination schedules. At the level of member states, we consulted Ministries of Health and regulatory authorities' websites in the respective languages (German, French, Dutch). In the case of Italy, however, we primarily relied on secondary literature published in Eurosurveillance, a very prominent academic outlet for EU-based public health scholarship.

\section{Understanding variation}

\section{Following the historical path of voluntary vaccination: principles and particularities of Austrian immunization policy}

Austria's public health policy is based on equity (regardless of income and nationality), statutory insurance, and solidarity. Jointly funded by insurance contributions, and central and regional governmental subsidies, the NIP is free at the point of care 
for those vaccines included in the NIP. Optional vaccines such as those against tickborne encephalitis (TPE) and influenza are available by paying the provider or are subsidized by some social insurers (Fig. 1). Providers range from general practitioners (GPs) and pediatricians to public vaccination centers.

This fragmentation of funding and administration is due in part to the federal nature of public health in Austria that is regulated nationally but implemented by the federal states (Bundesländer), much as is the case in Germany. Due to this fragmentation, there is no reminder system (or 'call-recall system') in place, and infant and adult vaccination relies strongly on the individual initiative of parents, caregivers, or GPs. Likewise, the monitoring of vaccination rates takes place only at the local level and depends on various methods. Criticism of the lack of a central vaccination registry re-emerged recently with the advent of new vaccines such as those against hepatitis B and human papilloma virus (HPV), but criticism has not yet led to action at the political level [8].

In contrast to the loose organization of the NIP, it does define responsibilities and risks fairly strictly. First, only medical doctors administer vaccines, rather than certified nurses. Second, the national vaccination expert committee clearly specifies target groups and updates them annually - the evidence and considerations feeding into these decisions, however, are generally not published [8]. For influenza vaccine, the committee defines target groups generously and inclusively, and rationing in vaccination policy is rarely discussed openly-perhaps for fear of risking the already low adherence to national vaccination recommendations. The sensitive nature of defining who is at risk became acutely political in the recent case of HPV, when Austria introduced HPV vaccination for both girls and boys at the age of 9 years. This is in stark contrast to more restrictive recommendations of virtually all other EU countries, where the HPV vaccine is offered to girls only.

Despite the comparatively low vaccination coverage in Austria (below 80\% for MMR, [14]), former Minister of Health Pamela Rendi-Wagner, an immunologist by training, declared the introduction of mandatory vaccination "out of the question" [16]. At the same time, the national Bioethics Commission issued a non-binding recommendation that Austria introduce mandatory vaccination for healthcare workers (HCW). Against this background, it is interesting to observe which instruments are used to raise vaccination coverage. The public funding of vaccination clearly acts as an incentive for vaccination. The NIP relies primarily on information and capacity-building instruments, such as the paper-based vaccination card that is affixed to the mother-child health card that includes information on recommended vaccines. The recent suggestion to try electronic vaccination registries in some regions of Austria, including its capital, promises to increase vaccination rates by actively reminding target groups of recommended vaccines [17].

Such capacity-building efforts are in place to strengthen individual agency, without altering the overall system or introducing new behavioral instruments. Given the lack of a reminder system and the fragmented nature of data collection on vaccination rates in Austria, the effectiveness of the NIP is largely reliant on the individual initiatives of providers, parents, and caregivers, rather than genuine behavioral 
instruments in Austrian vaccination policy (“classical approaches," Fig. 1). We find no genuine efforts to modify the 'choice architecture' in vaccination policy. We consider the Austrian approach to vaccination to be shaped by the premise of preserving the right to bodily integrity, rather than liberal values of individual choice. Typically, Austrian policy moves incrementally, and behavioral insights are not prominent in the current policy discourse.

\section{Guiding pro-vaccination behavior in the Netherlands: principles and practice}

The Dutch NIP is tax-funded, and is based on the principles of equal access and solidarity (Fig. 1). The National Institute for Public Health and the Environment (RIVM) manages a central digital vaccination registry that holds individual-level data. The results of this monitoring provide impressive data: the Netherlands has a very high vaccination uptake of up to $97 \%$ [18] in the case of MMR vaccine (against measles, mumps, and rubella), often considered an indicator of the quality of public health systems and NIPs specifically.

The Dutch NIP remains entirely voluntary, but a digital call-recall system is in place to invite eligible citizens for vaccination, which ensures a higher level of coverage. Furthermore, target groups are defined and this is communicated very clearly to parents, employers, and through the media. The Netherlands applies a mix of policy instruments that pave the way for high vaccination rates. By exploring the role of the policy infrastructures that underlie public health policy in the Netherlands, Paul et al. [19] point to the highly institutionalized role of youth health services and the structured approach to vaccine policies in this context, and suggest that most parents in the Netherlands perceive immunization as something that is quasi-compulsory [19]. This perception is reaffirmed by the systematized nature of the NIP. Parents of infants receive written invitations for vaccinations along with forms to present any objections (mainly based on religious grounds). The NIP provides objection forms to members of the Reformed Protestant communities, as they oppose vaccination on religious grounds; however, so do 'critical parents' who fear side effects and adverse reactions, or believe that vaccination may impair their child's developing immune system $[6,19,20]$. At this point, only religious grounds are listed in the exemption forms.

While the 'critical parents movement' is typically marginalized in political discourse, it is simultaneously embedded in the NIP: 'anthroposophical' health centers offer alternative vaccination schedules [19, 21]. 'Anthroposophists'-who adhere to a school founded by Rudolf Steiner-do not necessarily reject all vaccinations, but believe that natural means should be employed to optimize child development and health. Should parents not want to, or forget to have their infant vaccinated, but fail to send an objection note, regional health authorities make contact through healthcare visitors to check on that family. Likewise, data collection on vaccination behavior is of paramount concern to RIVM (National Institute for Public Health and the Environment), that collates individual-level data on the Dutch population and is able to link vaccination records to population registers. Overall, the Dutch focus on 
'structuring choices' and using data to reach target groups more effectively is reasonably consistent with what is known as a 'technocratic,' science-based approach.

The interplay of policies and instruments demonstrates the highly programmatic, innovative nature of the Dutch NIP (Fig. 1). Our review indicates that governing behavior, by designing a highly structured public health infrastructure, is effective in some countries and leads to less resistance than, for instance, vaccine mandates. These insights about the importance of institutional design should be considered when rethinking existing immunization programs. The question then becomes less about whether mandatory vaccination should be introduced or not, but what scope there is within existing systems to improve effectiveness by considering the ways in which vaccine administration also reflects an encounter between the state and its citizenry.

\section{The case of Germany: the rise of new steering instruments}

Financing for the NIP in Germany was formalized only recently following many years of pressure by public health experts. In 2007, the federal government created an initial legal basis for the categorical reimbursement of vaccinations through Statutory Health Insurance. The reimbursement is closely linked to the vaccination recommendations of a federal institution, the "Ständige Impfkommission" (STIKO, Permanent Vaccination Commission). The STIKO is an independent expert body that continuously evaluates data on vaccinations and vaccine-preventable diseases. Citizens (or their caregivers) may choose a provider: GPs, pediatricians, and clinicians in public health clinics are all permitted to administer vaccines.

Vaccination has been voluntary since the mid-1960s, but recently, parents have been required to provide proof of a medical consultation on vaccination in order to access public childcare. Political actors in Germany have continuously sought (and struggled) to design a vaccination policy that reconciles the duty to protect public health and the right to self-determination. Legal and bioethical experts have frequently cited the conflict between these two aspects as an argument against mandatory vaccination [13]. From an historical point of view, it is evident that since the 1950s, there has been a shift away from public health and toward the pre-eminence of individualized medicine, including such immunization programs that focus on the individual. Physicians in private practices have typically administered vaccines, which, until 2007, were not generally reimbursed through public health insurance, as mentioned above. This lack of formalization had a negative effect on vaccination uptake. Although reimbursement is now guaranteed, "severe and potentially dangerous vaccination gaps occur locally" [22] as studies have shown with regard to measles. A comparison between the federal states reveals a mixed picture. For historical reasons, we find a higher degree of institutionalization under the public health service in East German federal states, and that results in higher rates of vaccination [22, 23].

To sum up, reimbursement for the costs of vaccination has paved the way for the systematic promotion of the willingness to vaccinate (Fig. 1). There are authoritative and incentivizing instruments, as well as information provision and an 
institutionalized infrastructure. Beyond this, we find some use of persuasive instruments in German vaccination policy in cities, addressing those born after 1970, to promote vaccination against MMR: "Deutschland sucht den Impfpass" ("Germany searching for the vaccination card"). This campaign primarily targets an urban anthroposophical milieu.

Finally, we are seeing an initial step toward what we could call 'indirect mandatory vaccination': public childcare providers can now demand proof of specific vaccinations in specific situations. All in all, Germany has a complex structure of institutions to prevent infection and a mixture of traditional policy instruments. Vaccination policy in Germany aims to ensure protection against infectious diseases without restricting the autonomy of the individual unnecessarily, resulting in a classical-voluntary NIP.

\section{France-past and present meanings of the vaccine mandate}

Much like its European counterparts, the French state offers national health insurance that covers vaccinations if the vaccines are approved by the state. This obligation to adhere to officially recommended vaccines and timelines suggests a stronger focus on monitoring general practitioners' compliance, rather than that of patient-citizens.

The French NIP has long featured three mandatory vaccinations (DTP: diphtheria, tetanus, and pertussis) — a fact that has often been overlooked in recent media coverage of the recently extended vaccine mandate. Mandatory vaccination against DTP dates back to the 1950s and is the historical drive to eradicate diseases (such as polio), rather than simply to protect individuals. Historically, then, the French government has not shied away from applying coercive instruments (Fig. 1). Contemporary French vaccination policy still features a comparatively hierarchical approach: Public health insurance reimburses vaccines only if they are used according to the national recommendation guidelines. This could be understood as a typical incentivizing instrument with some behavioral facets targeting health professionals and nudging them to comply with official guidelines [24].

Much like other high-income countries, France has witnessed the growth of an anti-vaccine movement since the 1990s [25]. The emergence of new vaccines that provoke contentious reactions, such as those against Hepatitis-B and HPV [7] and the large-scale vaccination campaign against influenza H1N1 in 2009 [25] may have fueled vaccine hesitancy even further in recent years. Vaccine hesitancy among health professionals themselves [26] arguably exacerbates the political challenge even further.

In light of falling vaccination coverage, in 2012, the French government launched a five-year national action plan to improve vaccination coverage. At the level of the overall system, the action plan included calls for simplifying guidelines, reducing complexity of decision-making, and improving transparency. As far as actors are concerned, the report specifically called on the Regional Health Agencies to improve coordination of vaccination facilities with the aim of improving access [24]. Importantly, the action plan also called for technological innovation by means 
of establishing of an electronic vaccination record to integrate with electronic health record, thus likely enabling informed decisions.

In combination with this policy of persuasion aimed at strengthening capacity, we also find organizational tools to reinforce citizens' willingness to be vaccinated (Fig. 1). As part of this national action plan, in 2016, the French Ministry of Health took the unprecedented step of launching a citizen consultation on the question of mandatory vaccinations. Although it concluded in favor of a mandate, this proposal has not been universally endorsed. Critics of the mandate fear that it will create more resistance and fail to address the challenge of increasing vaccine hesitancy [27]. Nonetheless, the number of mandatory vaccines was increased from 3 to 11 as of January 2018. Parents who refuse to vaccinate their child can face fines and imprisonment for up to 6 months [28].

Even in this new era of a mandatory and participatory NIP, monitoring is of key importance, and yet data collection on vaccination coverage is decentralized, much as in Austria and Germany, and is largely a matter for France's régions. The central public health agency, Santé Publique France, carries out monitoring and obtains data from all regions which are then aggregated with some delay. It remains to be seen how the new vaccine mandate fares in France, but resistance is likely. The difficulty of obtaining reliable coverage data may also make monitoring the effects of the new mandate more difficult.

The case of France shows that the literature on immunization programs (which differentiates between voluntary and mandatory vaccination) - as well as political debates that reproduce this binary distinction-need to be overhauled to allow for a more nuanced understanding of vaccination programs.

\section{Immunization policy in Italy: move toward a full vaccine mandate in response to populist influences}

Much like its French counterpart, the Italian NHS has long featured a hybrid approach to immunization, whereby four vaccines have been mandatory for some time (diphtheria, hepatitis B, polio, tetanus). The Italian National Health System covers vaccination, but responsibility for public health is shared between national and regional authorities (Fig. 1). This leads to a wide range of practices, including different vaccine registries [29] in Italy's 21 regions, with more regional power than in the other cases presented.

This heterogeneity proved to be a challenge during the $2009 \mathrm{H} 1 \mathrm{~N} 1$ influenza pandemic [30], but it also allowed for local policy experimentation: in 2008, the Veneto region ended all mandatory vaccination [31]. The coverage trend for the first affected birth cohort showed a slight decline in immunization uptake for previously mandatory vaccinations, but vaccination coverage remained above the objective of 95\% [30, 32], thus encouraging those who favor a non-mandatory NIP. Other commentators interpreted this policy experiment as a failure, because polio vaccinations declined in the Veneto region [33]. This example underlines the political factors involved in interpreting coverage rates and the results of regional experiments. 
In May 2017, Italy announced moves toward a comprehensive vaccine mandate in its new NIP, the Piano Nazionale Prevenzione Vaccinale. Children must be vaccinated against 12 illnesses before they may enroll at state-run nurseries and schools. Parents who refuse the mandate face hefty fines and possibly other legal consequences. In his announcement, Prime Minister Paolo Gentiloni referred to the dramatic increase in cases of measles in Italy in 2017. Indeed, Italy had the sixthhighest incidence of measles that year [34]. Gentiloni blamed the fall in the vaccination rate partly on the "spread of anti-scientific theories" [35]. The vaccination controversy, however, was part of more general political crisis. The Five Star Movement (M5S) nurtured vaccine hesitancy by publicly questioning the safety of vaccines and opposing the vaccine mandate, framing it as a "gift" to the pharmaceutical industry [36]. After winning the largest number of seats in parliament in the Italian legislative elections of April 2018, and proceeding to form a coalition government, M5S immediately moved to end mandatory vaccination by voting to amend the law that had been introduced by the previous government. Interestingly enough, in the case of vaccination against measles the government has announced that they "will uphold the obligation for children up to the age of 16 (to be vaccinated)" in order to avoid a measles outbreak [37]. However, vaccination policy in Italy is characterized by several "u turns" [38], making it difficult to predict what the NIP will offer in the future. The latest reports from Italy point to the fragility of the NIP-likely as a reflection of Italian politics overall-and the potential to be undermined by political movements that seek to discredit the role of scientists providing advice to governmental authorities [38].

Public health experts had commented approvingly on the Italian mandate, as vaccination rates for polio and MMR had increased [32]. We, however, argue that the mandate fails to address certain relevant issues that are not epidemiological in nature: access to vaccines by appropriate funding, infrastructure and information, adequate monitoring, and increased trust in both the state authorities and medical institutions are all required if we are to sustain herd immunity, and to address related urgent public health issues, such as antimicrobial resistance. Apart from the uncertain public health impact of Italy's vaccine mandate, its political motivation and overall impact are also questionable.

\section{Discussion}

The variety of NIPs covered here leads us to several tentative conclusions. First, the organization of NIPs varies in terms of the looseness or rigidity of the role of the state. While some NIPs, such as those of Austria and Germany, rely primarily on the initiative of citizens or medical professionals, other systems, such as in the Netherlands, feature strong incentives and behavioral tools. While formally voluntary in nature, the Dutch NIP combines strong institutions with subtle mechanisms that promote (pro-vaccination) behavior. At the other end of the spectrum, France and Italy have always enforced some degree of mandatory vaccination, the legacy of a time when the eradication of disease was the dominant discourse that shaped European public health systems. 
This does not, however, mean that states can be grouped as either 'favoring coercive measures' (mandates) or as 'upholding liberal notions of autonomy' (voluntariness). All democratic states face the same challenge of balancing the often-conflicting aims of protecting public health and individual autonomy at the same time. Nevertheless, vaccine mandates are not the answer to this fundamentally irreconcilable conflict, as they are likely to generate even more resistance. Our insights about the importance of institutional design indicate that the question is less about whether vaccine mandates should be introduced or not, but how to improve the transparency of existing systems for those with concerns or questions. Vaccination programs not only mirror, but also reproduce the ways in which state-society relationships are conceptualized in a given country [32]. For example, to focus on increased transparency, when offering vaccination, more resources could be devoted to addressing individual and parental concerns. After all, these are fundamental encounters between the state and its citizenry. In other words, enhancing vaccine confidence requires building trust in the political system in the first place.

That said, vaccine skepticism has many origins, and its manifestations vary significantly across contexts [9]. Its most recent expression, however, has been associated with anti-establishment movements across the political spectrum: in Italy, with the Five Star Movement (M5S), in the United States, with Mr. Trump's comments about vaccine safety, in Greece, with the decision of Syriza to end the Greek vaccine mandate, and in France with comments made by the Front National [39]. If vaccine mandates are political projects to reassert the power of state institutions and the authority of medicine, they may increase vaccine uptake in the short run but fail to tackle the apparent erosion of social and political trust in the authorities of both the state and science.

A second conclusion concerns the politics of monitoring. The diversity in monitoring practices is astonishing given the prominence of vaccination coverage as a proxy indicator for the quality of primary healthcare systems [40]. The lack of precision in some monitoring practices not only hampers the evaluation of campaigns and instruments, but also contributes to the polarized nature of the current policy discourse. That is because it separates vaccinated segments of the population from those who decline immunization. In order to ensure that policy is evidence based, we not only need better data collection, but also more inclusive forms of evidence. Parents, adolescents, caregivers, school doctors, and medical professionals hold a range of experiential and ethical knowledge that should be used to improve vaccination programs based on how they are perceived and experienced by those who use them.

Registries can be used to send reminders to those due for vaccination; but more than this, they can also be used to present transparent data both on adverse reactions to vaccinations as well as on the benefits of vaccinations. This could boost the effectiveness of vaccination programs by enhancing public confidence in the safety of vaccines [41], and also in the integrity of the underlying infrastructure, which seems to have been compromised, as suggested in a recent New York Times opinion piece in the US context [42]. In addition, joint EU-wide monitoring efforts could complement the research that is needed to improve the safety and effectiveness of vaccines. 
Finally, as recent political debates in Italy indicate, vaccination programs, as historically shaped and path dependent as they may seem, are not immune to the influence of populism. References to absolute knowledge, certainty, and the safety of vaccines are pervasive in vaccination policy discourse, but have not helped to restore public trust. Social scientists need to explore, not only why a few people choose not to vaccinate their children, but also why the overwhelming majority (in the case of measles) still do choose to do so. Understanding how and why citizens value public health interventions would yield important policy knowledge, and those values could, in turn, be harnessed to improve access, organization, and supply.

Acknowledgement Open access funding provided by University of Vienna. We thank Katharina Riesinger for her research assistance and close reading of earlier drafts.

Open Access This article is distributed under the terms of the Creative Commons Attribution 4.0 International License (http://creativecommons.org/licenses/by/4.0/), which permits unrestricted use, distribution, and reproduction in any medium, provided you give appropriate credit to the original author(s) and the source, provide a link to the Creative Commons license, and indicate if changes were made.

\section{References}

1. Freeman Phyllis. The biology of vaccines and community decisions to vaccinate. Public Health Rep. 1997;112(1):21.

2. Fine P, Eames K, Heymann DL. "Herd immunity": a rough guide. Clin Infect Dis. 2011;52(7):911-6.

3. Anderson RM, May RM. Vaccination and herd immunity to infectious diseases. Nature. 1985;318:323-9.

4. Kieslich K. Addressing vaccination hesitancy in Europe: a case study in state-society relations. Eur J Public Health. 2018;28(3):30-3.

5. For the typical libertarian reflex towards this in the USA see e.g. Colgrove J. Immunity for the people: the challenge of achieving high vaccine coverage in American history. In: Schwartz JL, Caplan AL, editors. Vaccination ethics and policy. Cambridge: MIT Press; 2007.

6. Blume S. Anti-vaccination movements and their interpretations. Soc Sci Med. 2006;62(3):628-42.

7. Löwy I. HPV vaccination in context: a view from France. In: Wailoo K, Livingston J, Epstein S, Aronowitz R, editors. The HPV vaccine controversies. New Brunswick: Rutgers University Press; 2010. p. 270-92.

8. Paul KT. 'Saving lives': adapting and adopting HPV vaccination in Austria. Soc Sci Med. 2016;153:193-200.

9. Hobson-West P. Understanding vaccination resistance: moving beyond risk. Health Risk Soc. 2003;5(3):273-83.

10. Pelullo CP, Marino S, Valdes Abuadili AJ, Signoriello G, Attena F. Is it reasonable to abandon obligatory vaccinations in Italy? EuroSurveillance 2014; http://www.eurosurveillance.org/ViewArticl e.aspx?ArticleId=20889. Accessed 1 July 2018.

11. Loer K. Approaches and instruments in health promotion and the prevention of diseases (Chapter 3). In: Ewert B, Loer K, editors. Understanding the challenges of policy-making in public health. Cham: Palgrave; 2019.

12. The Lancet (2018) Addressing decreasing vaccine coverage in the EU. Editorial. 2018; 391: 1638.

13. Loer K. Gesundheitspolitik zwischen Schutzpflicht und Eigenverantwortung. Das Beispiel der Impfpolitik in Deutschland. In: Pünder H, Klafki A, editors. Schriften der Deutschen Sektion des Internationalen Instituts für Verwaltungswissenschaften, Band 40. Baden-Baden: Nomos; 2016. p. 81-103.

14. OECD Country Report Austria. OECD Doing Better for Children. Paris: OECD; 2015.

15. European Center of Disease Control (ECDC). https://vaccine-schedule.ecdc.europa.eu. Accessed 1 June 2018.

16. Masern: Rendi-Wagner gegen generelle Impfpflicht, 2017, Der Standard (Austrian daily newspaper), 12 March.

17. OTS (Austrian Press Agency) Wien führt elektronischen Impfpass ein, 21 November 2018. Press Release. 
18. RIVM, The National Immunisation Programme in the Netherlands. Developments in 2016. Bilthoven: RIVM, 2016.

19. Paul KT, Wallenburg I, Bal R. Putting public health infrastructures to the test: introducing HPV vaccination in Austria and the Netherlands. Sociol Health Illn. 2018;40(1):67-81.

20. Streefland PH. Public doubts about vaccination safety and resistance against vaccination. Health Policy. 2001;55(3):159-72.

21. Geelen E, van Vliet H, de Hoogh P, Horstman K. Taming the fear of voice: dilemmas in maintaining a high vaccination rate in the Netherlands. Soc Sci Med. 2016;153:12-9.

22. Eichner L, Wjst S, Brockmann SO, Wolfers K, Eichner M. Local measles vaccination gaps in Germany and the role of vaccination providers. BMC Public Health. 2017;17(1):656.

23. Poethko-Müller C, Schmitz R. Vaccination coverage in German adults. BundesgesundheitsblattGesundheitsforschung-Gesundheitsschutz. 2013(5/6).

24. Loulergue P, Floret F, Launay O. Strategies for decision-making on vaccine use: the French experience. Expert Rev Vaccin. 2015;14(7):917-22. https://doi.org/10.1586/14760584.2015.1035650.

25. Ward JK. Rethinking the antivaccine movement concept: a case study of public criticism of the swine flu vaccine's safety in France. Soc Sci Med. 2016;159:48-57. https://doi.org/10.1016/j.socsc imed.2016.05.003.

26. Verger P, Collange F, Fressard L, Bocquier A, Gautier A, Pulcini C, Raude J, Peretti-Watel P. Prevalence and correlates of vaccine hesitancy among general practitioners: a cross-sectional telephone survey in France, April to July 2014. Eurosurveillance. 2016. https://doi.org/10.2807/1560-7917.

27. Ward JK, Colgrove J, Verger P. France's risky vaccine mandates. Science. 2017;358(6362):458-9. https ://doi.org/10.1126/science.aaq1682.

28. Sénécat A. Refus de vaccination: les sanctions seront-elles alourdies? Le Monde 31 Oct 2017. https:// www.lemonde.fr/les-decodeurs/article/2017/10/31/refus-de-vaccination-les-sanctions-seront-elles-alour dies_5208215_4355770.html. Accessed 1 July 2018.

29. Alfonsi V, D’Ancona F, Rota MC, Giambi C, Ranghiasci A, Iannazzo S. Regional coordinators for infectious diseases and vaccinations. Immunisation registers in Italy: a patchwork of computerisation. Eurosurveillance. 2012;17(17):20156.

30. Rizzo C, Rota MC, Bella A, Giannitelli S, De Santis S, Nacca G, Pompa MG, Vellucci L, Salmaso S, Declich S. Response to the 2009 influenza A(H1N1) pandemic in Italy. Eurosurveillance. 2010;15(49):19744.

31. Haverkate M, D’Ancona F, Giambi C, Johansen K, Lopalco PL, Cozza V, Appelgren E, on behalf of the VENICE project gatekeepers and contact points. Mandatory and recommended vaccination in the EU, Iceland and Norway: results of the VENICE 2010 survey on the ways of implementing national vaccination programmes. Eurosurveillance. 2012;17(22):20183.

32. Signorelli C, Iannazzo S, Odone A. The imperative of vaccination put into practice. Lancet Infect Dis. 2017;18(1):26-7. https://doi.org/10.1016/S1473-3099(17)30696-5.

33. Signorelli C, Odone A, Cella P, Iannazzo S, D'Ancona F, Guerra R. Infant immunization coverage in Italy (2000-2016). Annali dell'Istituto Superiore Di Sanita. 2017;53(3):231-7. https://doi.org/10.4415/ ANN_17_03_09.

34. http://www.who.int/immunization/monitoring_surveillance/burden/vpd/surveillance_type/active/big_ measles_reportedcases6months.png?ua=1. Accessed 1 June 2018.

35. BBC. Italy makes 12 vaccinations compulsory for children. 2017. http://www.bbc.com/news/world -europe-39983799. Accessed 27 July 2018.

36. The Guardian. Italy experiencing measles epidemic after fall-off in vaccinations. 2017. https://www. theguardian.com/world/2017/apr/19/italy-measles-epidemic-vaccinations. Accessed 27 July 2018.

37. Squires N. Italy's populist coalition renounces anti-vaccination stance amid measles 'emergency', The Telegraph, 15 November, https://www.telegraph.co.uk/news/2018/11/15/italys-populist-coalition-renou nces-anti-vaccination-stance/last. Accessed 19 Nov 2018.

38. Giuffrida A. Sacking of Italy's health experts raises political interference concerns, The Guardian, https ://www.theguardian.com/world/2018/dec/04/politically-motivated-italys-m5s-sacks-peak-board-ofhealth-experts/last. Accessed 12 Dec 2018.

39. Kennedy J, Michailidou D. Divergent policy responses to increasing vaccine skepticism in southern Europe. Lancet Infect Dis. 2017;17:900.

40. Guttmann A, Shulman R, Manuel D. Improving accountability for children's health: immunization registries and public reporting of coverage in Canada. J Paediatr Child Health. 2011;16(1):16-8.

41. Robbins A, Freeman P. Optimal disease prevention using vaccination depends on a system. Public Health Rep. 1998;113(6):533-4. 
42. Moyer MW. Anti-vaccine activists have taken vaccine science hostage. 2018, New York Times, 4 August, https://www.nytimes.com/2018/08/04/opinion/sunday/anti-vaccine-activists-have-taken-vacci ne-science-hostage.html. Accessed 6 Aug 2018.

Publisher's Note Springer Nature remains neutral with regard to jurisdictional claims in published maps and institutional affiliations.

Katharina T. Paul PhD, MA, is Senior Research Fellow at the University of Vienna, Department of Political Science, Vienna, Austria. Her research is funded by the FWF - Austrian Science Fund (Grant Agreement No V561) and the European Commission (Grant Agreement No 770523).

Kathrin Loer, Dr. rer. pol., is Senior Researcher at the FernUniversität in Hagen, Department of Political Science, Germany. 